\title{
O processamento silábico em crianças e sua relação com o processamento fonológico
}

\section{Syllabic processing in children and its relation to phonological processing}

\section{El procesamiento silábico y su relación com el procesamiento fonológico}

\author{
Francis Ricardo dos Reis J usti* \\ Universidade Federal de Juiz de Fora - UFJF, Juiz de Fora, Minas Gerais, Brasil \\ Cláudia Nascimento Guaraldo J usti** \\ Universidade Federal de Juiz de Fora - UFJF, Juiz de Fora, Minas Gerais, Brasil
}

\begin{abstract}
RESUMO
O presente estudo investigou o efeito de priming silábico e da estrutura silábica na leitura. Participaram dessa pesquisa 88 crianças falantes do português brasileiro que cursavam do $1^{\circ}$ ao $4^{\circ}$ ano do Ensino Fundamental. Utilizou-se uma tarefa de decisão lexical e observou-se um efeito de priming silábico no tempo de reação e um efeito da estrutura silábica na porcentagem de erros. A memória de trabalho fonológica correlacionou-se com o efeito da estrutura silábica, mas a consciência fonológica não. Nenhuma dessas variáveis se correlacionou com o efeito de priming silábico. Discutiu-se o papel do processamento fonológico no processamento da leitura.
\end{abstract}

Palavras-chave: consciência fonológica, memória, priming silábico.

\section{ABSTRACT}

The present study investigated the effects of syllabic priming and syllabic structure on reading. Eighty-eight Brazilian Portuguese speaking children in grades 1-4 took part in this study. A lexical decision task with words and pseudo words was employed. A significant syllabic priming effect was observed on participant's reaction time in the lexical decision task. A syllabic structure effect was observed on participant's accuracy in the lexical decision task. Neither phonological awareness nor phonological working memory correlated with the syllabic priming effect. Phonological working memory was the only variable to correlate with the syllabic structure effect. The role of phonological processing in reading processing was discussed.

Keywords: phonological awareness, memory, syllabic priming.

\section{RESUMEN}

El presente estudio investigó el efecto de priming silábico y la estructura silábica en la lectura. Participaron 88 alumnos, con portugués brasileño como idioma materno, que se encontraban cursando $1^{\circ}$ al $4^{\circ}$ año de la escuela primaria. Se utilizó una tarea de decisión léxica. Se observó un 
efecto de priming silábico sobre el tiempo de reacción y un efecto de la estructura silábica en la precisión. La memoria de trabajo fonológica presento una correlación con el efecto de la estructura silábica, pero no la conciencia fonológica. Ninguna de estas variables presento una correlación con el efecto de priming silábico. Se examinó la función de procesamiento fonológico en el procesamiento de la lectura.

Palabras clave: consciencia fonológica, memoria, priming silábico.

\section{I ntrodução}

A habilidade de ler está entre as aquisições mais significativas da mente humana e é uma das habilidades mais criticamente requeridas nas sociedades modernas. Assim sendo, não é por acaso que a habilidade de ler de forma hábil e o seu aprendizado estejam entre os temas mais pesquisados pela Psicologia Cognitiva (Andrews, 2006). Em especial, no que diz respeito à tradição de pesquisas acerca do reconhecimento visual de palavras, um dos aspectos mais estudados da leitura é o acesso lexical. O acesso lexical se refere ao acesso à representação mental das palavras que são reconhecidas em um texto, sendo um processo fundamental para a construção de uma boa compreensão do mesmo (Perfetti \& Hart, 2001).

Como o reconhecimento rápido e automático de uma palavra é uma condição sine qua non para uma leitura hábil, muitos estudos têm sido realizados acerca das variáveis que afetam o acesso lexical. Essas variáveis podem ser lexicais ou sublexicais. As variáveis lexicais são as mais estudadas e se referem às características de uma palavra, como, a sua frequência de ocorrência e sua regularidade do ponto de vista de um mapeamento grafema - fonema (ver o trabalho de Lúcio \& Pinheiro, 2011 para uma revisão dos estudos realizados com falantes da língua portuguesa acerca dessas variáveis). Já as variáveis sublexicais se referem às unidades representacionais menores que uma palavra como, por exemplo, padrões ortográficos, fonológicos e morfológicos que podem contribuir para o reconhecimento de uma palavra (Carreiras \& Grainger, 2004).

A sílaba é uma unidade sublexical que tem despertado interesse nas pesquisas cognitivas sobre o reconhecimento visual de palavras (Álvarez, Carreiras \& Perea, 2004; Ashby \& Rayner, 2004; Carreiras \& Perea, 2004, 2011; Chetail \& Mathey, 2009; Conrad, Carreiras, Tamm \& Jacobs, 2009; Conrad \& Jacobs, 2004; Maïonchi-Pino, Magnan \& Écalle, 2010). Um dos primeiros trabalhos que avaliou o papel da sílaba no reconhecimento visual de palavras foi realizado por Carreiras, Álvarez e de Vega (1993), com falantes do espanhol. Nesse estudo, os pesquisadores desenvolveram uma série de experimentos com a tarefa de decisão lexical e com a tarefa de leitura em voz alta. $\mathrm{Na}$ tarefa de decisão lexical, apresenta-se um estímulo no centro da tela de um computador e o participante deve apertar uma tecla se 
este estímulo for uma palavra conhecida ou apertar outra tecla se este estímulo for uma pseudopalavra (sequência de letras construída com estrutura ortográfica possível na língua em questão, mas não associada a nenhum significado). Nas duas tarefas de decisão lexical empregadas no estudo, os participantes responderam mais rapidamente quando a sílaba inicial de uma palavra era infrequente do que quando esta era frequente. O mesmo padrão foi observado na tarefa de leitura em voz alta, porém o efeito da frequência silábica foi menor.

Carreiras et al. (1993) argumentaram que a sensibilidade dos participantes à frequência das sílabas em seu estudo seria um indício de que as sílabas têm um papel no processo de ativação das unidades lexicais durante o reconhecimento de palavras. De acordo com os autores, ao ser processada, a sílaba inicial de uma palavra pré-ativa no léxico mental todas as palavras que começam com essa sílaba. Como as sílabas frequentes provavelmente ocorrem em mais palavras, isso explicaria porque as pessoas reconhecem mais rapidamente as palavras quando a sua sílaba inicial é infrequente, já que essas últimas pré-ativariam menos palavras no léxico, diminuindo o número de palavras competidoras durante o processo de acesso lexical. É interessante notar que em um estudo que manipulou a frequência de ocorrência da primeira e da segunda sílaba de pseudopalavras em experimentos com a tarefa de leitura em voz alta, Carreiras e Perea (2004) observaram que o efeito de frequência silábica se restringiu à frequência da sílaba inicial das palavras.

Desde o trabalho de Carreiras et al. (1993) outros estudos têm observado efeitos do processamento silábico na leitura hábil em falantes de diferentes línguas e em tarefas diferentes. Em um trabalho realizado com falantes do alemão, Conrad e Jacobs (2004) investigaram o efeito da frequência da sílaba inicial das palavras na tarefa de decisão lexical e na tarefa de identificação perceptual. Na tarefa de identificação perceptual empregada no estudo, a palavra alvo era apresentada de forma fragmentada na tela de um computador e os participantes controlavam o aparecimento dos sucessivos níveis de desfragmentação da palavra, que iam sempre da versão mais fragmentada da palavra alvo (mais difícil de reconhecer) à menos fragmentada (eram oito níveis de desfragmentação, sendo que o último nível correspondia à palavra não fragmentada). Os pesquisadores observaram que as palavras que tinham a sílaba inicial mais frequente demandavam mais níveis de desfragmentação para serem reconhecidas na tarefa de identificação perceptual e demandavam também mais tempo para serem reconhecidas na tarefa de decisão lexical.

Em um estudo que foi realizado com falantes da língua francesa, Chetail e Mathey (2009) utilizaram uma tarefa de decisão lexical e observaram um efeito da frequência silábica, tanto em estudantes 
universitários, quanto em alunos do quinto ano escolar (crianças com média de idade de 10 anos e 10 meses). Por fim, outra língua na qual também se tem indícios de processamento silábico é o Inglês. Em um estudo que investigou o movimento dos olhos durante a leitura silenciosa em falantes da língua inglesa, Ashby e Rayner (2004) relataram que os participantes passavam mais tempo fixando uma palavra alvo quando antes de mover seus olhos para essa palavra era apresentado um conjunto de letras, na posição textual em que essa palavra iria aparecer, que era inconsistente com a primeira sílaba dessa palavra alvo. É interessante notar que as línguas nas quais o processamento silábico durante a leitura tem sido demonstrado (espanhol, alemão, francês e inglês) variam bastante tanto no grau de sua consistência no mapeamento grafema - fonema, quanto na complexidade de sua estrutura silábica (Seymour, 2005), trazendo, assim, indícios de que o processamento silábico pode ser um mecanismo presente nos diferentes sistemas alfabéticos de escrita.

Embora exista um número razoável de estudos que investigaram o processamento silábico na leitura hábil, esse número se reduz bastante quando se consideram os estudos que investigaram esse tipo de processamento em crianças aprendendo a ler. Um estudo que investigou o efeito de frequência silábica em crianças falantes do idioma espanhol foi o de Gozález e Valle (2000). Os autores utilizaram as tarefas de decisão lexical e de leitura em voz alta e observaram um efeito geral consistente da frequência silábica nas duas tarefas para as pseudopalavras, mas não observaram o mesmo efeito de forma consistente para as palavras. No entanto, os pesquisadores não manipularam a frequência de ocorrência da primeira sílaba, mas sim a frequência de ocorrência geral das sílabas o que pode ter prejudicado a detecção do efeito, já que Carreiras e Perea (2004) demonstraram que o efeito de frequência silábica se restringe à frequência de ocorrência da primeira sílaba.

Outro estudo que investigou o efeito de frequência silábica no acesso lexical em crianças foi o estudo já citado de Chetail e Mathey (2009) que foi realizado com a tarefa de decisão lexical. No entanto, as crianças desse estudo já estavam em fase adiantada de aprendizagem da leitura (quinto ano) e, assim sendo, é importante investigar quando esse tipo de processamento silábico surge em crianças que estão aprendendo a ler. Pode-se dizer que o estudo que investigou o processamento silábico na leitura em um período do desenvolvimento mais amplo foi o de Maïonchi-Pino et al. (2010). Esse estudo contou com a participação de crianças francesas do primeiro, terceiro e quinto ano escolar (crianças com, aproximadamente, sete, nove e onze anos de idade, respectivamente). Para avaliar o processamento silábico, os pesquisadores utilizaram uma tarefa na qual as crianças tinham que julgar, o mais rapidamente possível, se uma sequência de duas ou 
três letras ocorriam no início de uma palavra. A manipulação relevante era se a sequência de letras era congruente ou não com a primeira sílaba das palavras (p.ex., 'par' e 'partir' são pares congruentes, enquanto 'pa' e 'partir' não). Os pesquisadores observaram que as crianças do quinto ano responderam mais rapidamente quando as letras eram congruentes com a primeira sílaba das palavras que tinham uma estrutura do tipo consoante vogal - consoante (CVC), independente da frequência de ocorrência dessa sílaba, enquanto nas crianças do primeiro e do terceiro ano, isso ocorreu apenas quando a frequência de ocorrência da sílaba era alta.

Um dos problemas com o estudo de Maïonchi-Pino et al. (2010) é que - mesmo não avaliou diretamente o processo de acesso à representação mental das palavras (acesso lexical). Como a tarefa utilizada requeria apenas que as crianças julgassem se um determinado conjunto de letras ocorria ou não no início de uma palavra, elas não precisavam, necessariamente, processar a palavra para serem bem sucedidas na tarefa, bastava que elas se concentrassem apenas em suas duas ou três letras iniciais para responderem com êxito. Destarte, pode-se dizer que, até o momento, nenhum estudo avaliou o processamento silábico utilizando uma tarefa que avalia mais diretamente o processo de acesso lexical, como a tarefa de decisão lexical ou a tarefa de leitura em voz alta, em um período amplo do aprendizado da leitura (os estudos de Chetail \& Mathey, 2009 e de Gozález \& Valle, 2000, que utilizaram a tarefa de decisão lexical, se limitaram a crianças de um ano escolar específico ou a crianças de um determinado nível de leitura).

Outra crítica que pode ser feita a alguns dos estudos que têm investigado o efeito de processamento silábico na leitura, como os estudos de Gozález e Valle (2000) e de Maïonchi-Pino et al. (2010), é que nem sempre é fácil distinguir o processamento ortográfico do processamento silábico, afinal, uma sílaba frequente também pode coincidir com um padrão ortográfico frequente, como um bigrama (par de letras que coocorre em uma determinada posição nas palavras de uma língua). Por exemplo, a sílaba 'ca' em 'casa', também coincide com o conjunto de letras 'ca' que, de acordo com o trabalho de Justi e Justi (2009a), é o bigrama mais frequente no início das palavras de 4 letras no português brasileiro. Como o estudo de Conrad et al. (2009) demonstrou que a frequência de ocorrência dos bigramas tem um efeito facilitador no reconhecimento de palavras que é independente da frequência silábica, torna-se importante controlar essa variável.

Um estudo que utilizou um procedimento bastante eficiente para se controlar quaisquer efeitos de redundância ortográfica das palavras foi o estudo de Carreiras e Perea (2011). Nesse estudo, os pesquisadores utilizaram a técnica de priming em uma tarefa de 
decisão lexical para investigar o processamento silábico em adultos falantes do espanhol. Assim sendo, a palavra alvo era precedida muito rapidamente por uma pseudopalavra cuja primeira sílaba podia coincidir ou não com a primeira sílaba da palavra alvo. Por exemplo, as pseudopalavras 'junas' ou 'junto' podiam preceder a palavra espanhola 'junio', sendo que, nesse caso, a primeira sílaba da pseudopalavra 'junas' - 'ju' - coincide com a primeira sílaba da palavra 'junio', enquanto a primeira sílaba da pseudopalavra 'junto' 'jun' - não coincide. Os pesquisadores observaram que quando a sílaba inicial das pseudopalavras e das palavras era a mesma, os participantes reconheciam as palavras mais rapidamente do que quando as sílabas não eram as mesmas. Como ambas as pseudopalavras compartilham as três primeiras letras com a palavra alvo, qualquer efeito devido à frequência de ocorrência dos bigramas iniciais pode ser descartado, uma vez que as letras iniciais e, consequentemente os bigramas, são os mesmos nas duas condições experimentais.

Considerando-se os estudos que têm sido desenvolvidos acerca do processamento silábico durante a leitura, pode-se dizer que, embora existam evidências razoáveis da ocorrência desse em leitores adultos falantes de diferentes línguas, existe uma clara lacuna na literatura da área no que tange aos efeitos do processamento silábico no acesso lexical em crianças aprendendo a ler. Dos poucos estudos realizados, esses, além de muitas vezes não permitirem distinguir 0 processamento ortográfico do processamento silábico, se restringiram a uma etapa específica do desenvolvimento (Chetail \& Mathey, 2009; Gozález \& Valle, 2000) ou não investigaram diretamente o processo de acesso lexical (Maïonchi-Pino et al., 2010).

Outra lacuna relevante na literatura da área é que nenhum estudo procurou estabelecer qualquer relação entre o processamento silábico e variáveis relacionadas ao processamento fonológico, como a consciência fonológica e a memória de trabalho fonológica (Wagner \& Torgesen, 1987). A consciência fonológica tem sido definida como a habilidade de refletir sobre os sons que compõem a fala (Bryant \& Bradley, 1987) e diversos estudos têm indicado que essa variável tem um papel importante no aprendizado da leitura (Bryant \& Bradley, 1987; Cardoso-Martins, 1995; Melo \& Correa, 2013; Roazzi, Roazzi, Justi \& Justi, 2013). Já a memória de trabalho fonológica pode ser caracterizada como a forma como a informação é codificada fonologicamente e armazenada por um período curto de tempo e existem diversos estudos indicando que crianças que têm dificuldade de leitura apresentam uma memória de trabalho fonológica pior do que crianças sem dificuldade de leitura (Barbosa, Miranda, Santos \& Bueno, 2009; Kudo, Lussier \& Swanson, 2015; Salles \& Parente, 2006). Assim sendo, devido à forte relação que essas variáveis têm com o aprendizado da leitura, torna-se importante investigar se 
existe uma relação entre o processamento silábico e as variáveis relacionadas ao processamento fonológico.

Considerando-se que poucos estudos investigaram os efeitos do processamento silábico no acesso lexical em crianças aprendendo a ler e que nenhum desses investigou se há relação entre o processamento silábico e o processamento fonológico, a presente pesquisa presta uma valiosa contribuição para a literatura da área ao investigar essas questões em crianças falantes do português brasileiro. Assim sendo, o presente estudo avaliou, por meio de uma tarefa de decisão lexical, se existe algum padrão de desenvolvimento no processamento silábico ao longo dos primeiros quatro anos do Ensino Fundamental e se existe alguma relação entre 0 processamento fonológico e o processamento silábico.

\section{Método}

Participantes

Esta pesquisa foi realizada em uma cidade de médio porte do estado de Minas Gerais. Participaram 99 crianças (54 meninas e 45 meninos) do primeiro ao quarto ano do Ensino Fundamental de uma escola particular que atende a crianças de classe média a alta. Dessas crianças, 16 eram do primeiro ano do Ensino Fundamental (média de idade $=80,18$ meses, $D P=5,07$ ), 19 eram do segundo ano (média de idade $=90,84$ meses, $\mathrm{DP}=3,08) ; 38$ eram do terceiro ano (média de idade $=100,51$ meses, $\mathrm{DP}=3,00) ; \mathrm{e}, 26$ do quarto ano (média de idade $=113,42$ meses, $D P=4,51$ ). Essa pesquisa foi aprovada por um Comitê de Ética em Pesquisa (Parecer 195.611) e a participação das crianças no estudo foi condicionada à assinatura por parte de seus responsáveis legais do Termo de Consentimento Livre e Esclarecido.

Instrumentos

\section{Medida de Consciência Fonológica:}

- Tarefa de Subtração de Fonemas (baseada na tarefa de subtração de fonemas de Rosner \& Simon, 1971). A tarefa de subtração de fonemas consiste na apresentação oral de uma palavra (p.ex.: /KaRta/) e o requerimento de que o participante, mentalmente, subtraia um som em particular (p.ex.: $/ K /$ ) e diga o som que permaneceu (p.ex.: /aRta/). O escore na tarefa consiste no número de itens respondidos corretamente. Essa tarefa foi aplicada nas crianças do primeiro e segundo anos do Ensino Fundamental e 
apresenta fidedignidade (alpha de Crombach) de 0,80, conforme 0 estudo de Justi e Roazzi (2012).

- Tarefa de Spoonerismo (tarefa adaptada por Cardoso-Martins, Haase, \& Wood, 1998, da Phonological Assessment Battery desenvolvida por Frederickson, Frith, \& Reason, 1997). Esta tarefa requer que o participante troque 0 primeiro som de duas palavras apresentadas um pelo outro (Ex.: /miLU veRdi/ = /viLU meRdi/). $\mathrm{Na}$ correção da tarefa adotou-se o seguinte critério para cada par de palavras: dois pontos para acertos nas duas palavras, um ponto para acerto em uma palavra e nenhum ponto em caso de se errar as duas palavras. Essa tarefa foi aplicada nas crianças do terceiro e quarto anos do Ensino Fundamental e apresenta fidedignidade (alpha de Crombach) de 0,88, conforme o estudo de Justi e Roazzi (2012).

\section{Medida de Memória de Trabalho Fonológica:}

- Subteste Dígitos da Escala de Inteligência Wechsler para Crianças WISC-III (Wechsler, 2002). Esse subteste é formado por dois conjuntos: Ordem Direta e Ordem Inversa. Na Ordem Direta, a tarefa da criança consiste em repetir uma sequência de dígitos na mesma ordem enunciada pelo examinador. Na Ordem Inversa, a tarefa da criança consiste em repetir uma sequência de dígitos na ordem inversa daquela enunciada pelo examinador. O subteste apresenta fidedignidade de 0,62 e foi administrado e corrigido conforme as instruções de seu manual (Wechsler, 2002).

\section{Medida de Processamento Silábico:}

- Desenvolveu-se uma Tarefa de Decisão Lexical com a técnica de priming silábico tendo como base o trabalho de Carreiras e Perea (2011). Nessa tarefa, a palavra alvo era precedida por uma pseudopalavra (prime) que podia ter a mesma sílaba inicial da palavra alvo ou não, sendo que as três primeiras letras da pseudopalavra e da palavra alvo eram sempre as mesmas. A pseudopalavra era sempre apresentada em letras minúsculas por $100 \mathrm{~ms}$ e a palavra alvo, que substituía o prime, era apresentada logo em seguida em letras MAIÚSCULAS. A manipulação experimental consistiu em um delineamento fatorial do tipo $2 \times 2$, sendo os fatores: 'estrutura da sílaba inicial' que podia ser do tipo consoantevogal (CV) ou consoante-vogal-consoante (CVC); e, 'priming silábico' que podia ser congruente (quando a sílaba inicial do prime e da palavra alvo eram a mesma, p.ex., 'sucam' - 'SUCOS' ou 'banfe' 'BANDO') ou incongruente (quando a sílaba inicial do prime e da palavra alvo eram diferentes, p.e.x, 'tacta' - 'TACHO' ou 'verar' 'VERSO'). As palavras alvo consistiram em 40 palavras selecionadas do trabalho de Pinheiro (1996), sendo todas de baixa frequência de 
ocorrência para todas as séries investigadas (do primeiro ao quarto ano). Além disso, também foram controladas a frequência dos bigramas (Justi \& Justi, 2009a) e a frequência da sílaba inicial entre as palavras do tipo CV (20 palavras) e CVC (20 palavras). As palavras com sílaba inicial do tipo CV apresentaram média de frequência dos bigramas de 1475,70 tokens (desvio-padrão de 580,62) e média de frequência da sílaba inicial de 537,85 tokens (desvio-padrão de 580,62 ). As palavras com sílaba inicial do tipo CVC apresentaram média de frequência dos bigramas de 1477,17 tokens (desvio-padrão de 623,95) e média de frequência da sílaba inicial de 532 tokens (desvio-padrão de 335,31). Além disso, para evitar que um participante fosse exposto a uma mesma palavra duas vezes (nas condições de prime congruente e incongruente), foram criadas duas listas de palavras de forma que, se uma palavra em uma lista tinha como prime uma pseudopalavra silabicamente incongruente, na outra lista essa palavra tinha como prime uma pseudopalavra silabicamente congruente. As listas foram contrabalanceadas entre os participantes. Por fim, para compor a tarefa de decisão lexical foram criadas 40 pseudopalavras. O efeito de priming silábico para cada participante foi definido como a diferença entre seu tempo de reação para as palavras que foram precedidas por pseudopalavras silabicamente incongruentes e seu tempo de reação para as palavras que foram precedidas por pseudopalavras silabicamente congruentes.

\section{Procedimentos}

Os participantes foram testados individualmente em uma sala cedida pela direção da escola. O período de testagem consistiu em uma única sessão de, aproximadamente, 30 minutos. A tarefa de decisão lexical era realizada primeiro, sendo seguida das tarefas de consciência fonológica e de memória de trabalho fonológica. A tarefa de decisão lexical foi aplicada utilizando-se um notebook de arquitetura IBM - PC com uma tela de 14". A apresentação dos estímulos, registro do tempo de reação e dos acertos e erros foi realizada por meio do programa DMDX (Forster \& Forster, 2003). A tarefa de decisão lexical contou com uma sessão de treinamento e a dinâmica de apresentação dos estímulos na sessão de treinamento e experimental foi a seguinte: a marca de fixação ' + ' era apresentada por $500 \mathrm{~ms}$ e logo após era substituída pela pseudopalavra prime por $100 \mathrm{~ms}$, período após o qual, o prime era substituído pela palavra ou pseudopalavra alvo. O prime era sempre apresentado em letras minúsculas e 0 alvo em letras capitulares. $O$ estímulo alvo permanecia na tela até que a criança respondesse ou por um período de cinco segundos que era o tempo limite para a resposta. As crianças deviam pressionar um botão da cor verde, caso o estímulo 
alvo fosse uma palavra, ou um botão da cor vermelha, caso o estímulo fosse uma pseudopalavra.

\section{Resultados}

Foram excluídos os dados de todos os participantes que apresentaram $40 \%$ ou mais de erros na Tarefa de Decisão Lexical. Isso implicou na exclusão dos dados de 12 participantes, sendo dez do primeiro ano, um do segundo ano e um do terceiro ano. Assim sendo, a amostra final desse estudo foi de 87 crianças do primeiro ao quarto ano do Ensino Fundamental. Para compensar essa perda de participantes, optou-se por analisar os dados das crianças do primeiro e segundo anos juntas e os dados das crianças do terceiro e quarto anos juntas, a fim de aumentar o poder estatístico das análises. Além disso, como o teste de consciência fonológica do $1^{\circ}$ e $2^{\circ}$ anos foi a Tarefa de Subtração de Fonemas e o teste de consciência fonológica para 030 e 40 anos foi a Tarefa de Spoonerismo, isso facilitou as análises de correlação, já que as mesmas foram realizadas de acordo com esses grupos e não na amostra como um todo.

\section{Análises da Tarefa de Decisão Lexical}

Para lidar com a distribuição positivamente assimétrica dos escores de tempo de reação (TR), aplicou-se o método das medidas semirestringidas (Perea, 1999) e todos os escores de um participante que se desviavam de sua média por mais de dois desvios-padrão foram limitados a esse valor. Esse procedimento alterou 3,44\% dos escores de TR e resultou em uma distribuição normal, tanto para os dados do $1^{\circ}$ e $2^{\circ}$ anos, quanto para os dados do $3^{\circ}$ e $4^{\circ}$ anos, conforme testes Kolmogorov-Smirnov (todos os $p>0,14$ ). Os participantes do $1^{\circ}$ e $2^{\circ}$ anos apresentaram uma média de porcentagem de erros geral (incluindo palavras e pseudopalavras) de $19 \%$ ( $D P=6,7$ ) na Tarefa de Decisão Lexical, enquanto os participantes do $3^{\circ}$ e $4^{\circ}$ anos apresentaram uma média de porcentagem de erros de $11,96 \%$ (DP $=$ $6,4)$. Ao contrário do TR, de uma forma geral, a porcentagem de erros por condição experimental não apresentou uma distribuição normal, nem para as crianças do $1^{\circ}$ e $2^{\circ}$ anos (testes de Kolmogorov-Smirnov foram significantes para as condições CVC com prime congruente e incongruente, $p<0,03$ e $p<0,01$, respectivamente), nem paras as do $3^{\circ}$ e $4^{\circ}$ anos (testes de Kolmogorov-Smirnov foram significantes para todas as condições experimentais, todos os $p<0,02$ ). A Tabela 1 apresenta as estatísticas descritivas do TR e da porcentagem de erros dos participantes para as palavras por condição experimental na tarefa de decisão lexical. 
Tabela 1

Média e Desvio Padrão do TR e da Porcentagem de Erros na Tarefa de Decisão Lexical por Ano e Condição Experimental

\begin{tabular}{|c|c|c|c|c|c|}
\hline \multicolumn{2}{|c|}{ Condição Experimental } & \multicolumn{2}{|c|}{$1^{\circ} \mathrm{e} 2^{\circ}$ anos } & \multicolumn{2}{|c|}{$3^{\circ}$ e $4^{\circ}$ anos } \\
\hline \multirow[t]{3}{*}{ Silaba Inicial } & Prime & TR & $\% \mathrm{ER}$ & TR & $\% \mathrm{ER}$ \\
\hline & & $\mathrm{M}(\mathrm{DP})$ & $\mathrm{M}(\mathrm{DP})$ & $\mathrm{M}(\mathrm{DP})$ & $\mathrm{M}(\mathrm{DP})$ \\
\hline & Incongruente & $2172(482)$ & $24,0(11,9)$ & $1647(358)$ & $18,5(12,5)$ \\
\hline & Congruente & 2011(409) & $32,4(13,6)$ & $1640(372)$ & $18,9(12,3)$ \\
\hline \multirow{2}{*}{ CVC } & Incongruente & $2186(534)$ & $9,2(10,4)$ & $1683(456)$ & $6,3(9,8)$ \\
\hline & Congruente & 2149 (553) & $10,8(10,8)$ & $1660(480)$ & $7,7(8,8)$ \\
\hline \multicolumn{6}{|c|}{ Nota $\mathrm{CV}=$ consoante - vogal $(\mathrm{p} . \mathrm{ex}$ : ' febre'); $\mathrm{CVC}=$ consoante - vogal - consoante } \\
\hline
\end{tabular}

Como as pseudopalavras foram criadas apenas para compor a tarefa de decisão lexical, a análise dos efeitos de priming silábico e de estrutura silábica foi realizada levando em consideração os escores dos participantes nas palavras. Para a análise dos dados de tempo de reação, foi realizada uma ANOVA do tipo $2 \times 2 \times 2 \times 2$, tendo como fatores within-subjects a estrutura da sílaba inicial (CV $\times$ CVC) e 0 tipo de prime (Incongruente $x$ Congruente) e como fatores betweensubjects 0 ano escolar ( $1^{\circ}$ e $2^{\circ}$ anos $\times 3^{\circ}$ e $4^{\circ}$ anos) e a lista (Lista 1 $x$ Lista 2 ). Os resultados evidenciaram que o efeito principal de priming silábico foi estatisticamente significativo, $F(1,83)=4,57, p=$ $0,035, r=0,23$ (conforme sugerido por Rosenthal, 1984, optou-se por empregar $r$ como medida da magnitude do efeito para todos os testes desse estudo), sendo as palavras precedidas por primes congruentes reconhecidas cerca de 57 milissegundos mais rápido do que as palavras precedidas por primes incongruentes. Além disso, não houve interação estatisticamente significativa entre o tipo de prime e $o$ ano escolar $(p>0,11)$ e nem entre o tipo de prime e a estrutura silábica inicial $(p>0,20)$. O efeito de ano escolar também foi significativo, $F(1,83)=25,5, p<0,001, r=0,48$, sendo as crianças do $3^{\circ}$ e 40 anos cerca de 482 milissegundos mais rápidas do que as crianças do $1^{\circ}$ e $2^{\circ}$ anos. O efeito principal de estrutura 
silábica ficou próximo do nível alfa esperado, $F(1,83)=3,34, p=$ $0,07, r=0,20$. Por fim, nenhum outro efeito ou interação foi estatisticamente significativa (todos os valores $p>0,11$ ).

Como, no geral, os escores relativos à porcentagem de erros por condição experimental não apresentaram distribuição normal, optouse por comparar as médias de interesse por meio dos testes nãoparamétricos. Os resultados revelaram que as crianças do $1^{\circ}$ e $2^{\circ}$ anos apresentaram maior porcentagem de erros nas palavras do que as crianças do $3^{\circ}$ e $4^{\circ}$ anos, Mann-Whitney $\mathrm{U}=380,5, \mathrm{z}=-3,74, \mathrm{p}<$ $0,001, r=0,40$. Para as comparações within-subjects utilizou-se 0 teste de Wilcoxon. As crianças do $1^{\circ}$ e $2^{\circ}$ anos apresentaram maior porcentagem de erros nas palavras com estrutura silábica inicial do tipo CV do que nas palavras com estrutura silábica inicial do tipo CVC, $z=-4,21, p<0,001, r=0,84$. Além disso, elas apresentaram maior porcentagem de erros na condição de priming congruente do que na condição de priming incongruente, $z=-2,67, p<0,01, r=0,53$. As crianças do $3^{\circ}$ e $4^{\circ}$ ano apresentaram também maior porcentagem de erros nas palavras com estrutura silábica inicial do tipo CV do que nas palavras com estrutura silábica inicial do tipo CVC, $z=-5,82, p<$ $0,001, r=0,74$. Porém, as crianças do $3^{\circ}$ e $4^{\circ}$ anos não apresentaram diferença estatisticamente significativa na porcentagem de erros entre as condições de priming incongruente e congruente, $z$ $=-0,75, p=0,453, r=0,10$.

Por fim, optou-se por realizar também testes t para avaliar o efeito de lexicalidade no TR. O efeito de lexicalidade refere-se à vantagem em TR para as respostas às palavras em relação às pseudopalavras. Os resultados dessas análises evidenciaram que no $1^{\circ}$ e $2^{\circ}$ anos os participantes apresentaram um TR médio para responder às palavras de $2129 \mathrm{~ms}$ e um TR médio para responder às pseudopalavras de $2874 \mathrm{~ms}$, sendo essa diferença estatisticamente significativa, $\mathrm{t}(24)=$ 11,$96 ; p<0,001, r=0,93$. O mesmo padrão foi observado no $3^{\circ} \mathrm{e}$ 40 anos, sendo as palavras respondidas com um TR médio de $1657 \mathrm{~ms}$ e as pseudopalavras com um TR médio de $2234 \mathrm{~ms}$. Essa diferença foi estatisticamente significativa $t(61)=12,95 ; p<0,001$, $r=0,86$.

\section{Análises de Correlação}

Para avaliar se há alguma relação entre o processamento fonológico e o processamento silábico, o presente estudo realizou análises de correlação entre as medidas de consciência fonológica, memória de trabalho fonológica, efeito de priming silábico (diferença no TR entre primes incongruentes e congruentes) e a porcentagem de erros geral na tarefa de decisão lexical. Testes de normalidade foram realizados (Kolmogorov-Smirnov) e apenas a variável 'consciência fonológica' no $3^{\circ}$ e $4^{\circ}$ anos não apresentou distribuição normal $(p=0,04)$. Na 
Tabela 2 encontram-se os escores de correlação de Pearson para essas quatro variáveis por ano escolar. Apenas nas análises do $3^{\circ} \mathrm{e}$ $4^{\circ}$ anos que envolveram a variável 'consciência fonológica' os escores relatados se referem a análises de correlação de Spearman.

Tabela 2

Correlações Entre as Medidas de Memória de Trabalho Fonológica, Consciência Fonológica, Porcentagem de Erros e Efeito de Priming, Silábico por Ano Escolar

\begin{tabular}{ccccc}
\hline Medidas & MTF & CF & \%ER & E_Priming \\
\hline MTF & - & 0,16 & $-0,22$ & 0,07 \\
CF & $0,52^{* *}$ & - & $-0,07$ & $-0,01$ \\
\%ER & $-0,34^{* *}$ & $-0,33^{* *}$ & - & 0,26 \\
E_Priming & $-0,09$ & 0,06 & 0,00 & - \\
\hline
\end{tabular}

Nota. Correlações para crianças do $1^{\circ}$ e $2^{\circ}$ anos $(\mathrm{n}=25)$ são apresentadas acima da diagonal e correlações para crianças do $3^{\circ}$ e $4^{\circ}$ anos $(n=62)$ são apresentadas abaixo da diagonal.

$\mathrm{MTF}=$ Memória de Trabalho Fonológica; $\mathrm{CF}=$ Consciência Fonológica; \%ER = Porcentagem de Erros geral na tarefa de decisão lexical; E_Priming = Efeito de Priming no TR na tarefa de decisão lexical.

${ }^{* *} \mathrm{p}<0,01$

Como pode ser observado na Tabela 2, ao se considerar os dados das crianças no $1^{\circ}$ e $2^{\circ}$ anos, nenhuma das correlações atingiu o nível de significância estatística (todos os $p>0,2$ ). Já ao se considerar os dados das crianças no $3^{\circ}$ e $4^{\circ}$ anos, foi possível observar correlações estatisticamente significativas entre a memória de trabalho fonológica e a consciência fonológica $(\rho=0,52, p<0,01)$ e entre a porcentagem de erros e a consciência fonológica $(\rho=-0,33, p<$ $0,01)$ e a memória de trabalho fonológica $(r=-0,34, p<0,01)$. Nenhuma variável relacionada ao processamento fonológico se correlacionou com o efeito de priming silábico ou ficou próxima disso (todos os $p>0,4$ e o maior $r$ foi de $-0,09$ ).

Por fim, como foi possível observar um efeito da estrutura silábica na porcentagem de erros, optou-se por realizar análises de correlação de Spearman para investigar se houve correlação entre o efeito da estrutura silábica (calculado pela subtração da porcentagem de erros nas palavras com sílaba inicial CVC da porcentagem de erros nas 
palavras com sílaba inicial CV) e as variáveis do processamento fonológico. Para as crianças do $1^{\circ}$ e $2^{\circ}$ anos, nem a consciência fonológica, nem a memória de trabalho fonológica se correlacionaram com o efeito da estrutura silábica inicial $(\rho=0,02$ e $\rho=0,06$, respectivamente, todos os valores $p>0,77$ ). Já no caso das crianças do $3^{\circ}$ e $4^{\circ}$ anos a memória de trabalho fonológica correlacionou-se de forma fraca, mas estatisticamente significativa com o efeito da estrutura silábica inicial $(\rho=0,33, p<0,01)$, enquanto a consciência fonológica continuou sem se correlacionar com o efeito da estrutura silábica inicial $(\rho=-0,05, p>0,6)$.

\section{Discussão}

No que diz respeito às diferenças entre as faixas etárias (crianças do $1^{\circ}$ e $2^{\circ}$ anos comparadas às crianças do $3^{\circ}$ e $4^{\circ}$ anos), pode-se dizer que os resultados da tarefa de decisão lexical foram os esperados, isso é, as crianças mais velhas foram, no geral, mais rápidas e mais precisas (Lúcio \& Pinheiro, 2011). Além disso, em ambas as faixas etárias, as crianças reconheceram as palavras mais rapidamente do que as pseudopalavras, evidenciando o tradicional efeito de lexicalidade (Justi \& Justi, 2009b; Lúcio \& Pinheiro, 2011). Esse é um indício de que a tarefa de decisão lexical empregada no presente estudo foi adequada para as diferentes faixas etárias.

No que diz respeito à investigação do processamento silábico, esse estudo procurou avançar em relação aos estudos anteriores realizados com crianças (Chetail \& Mathey, 2009; González \& Valle, 2000; Maïonchi-Pino et al, 2010) ao investigar o processamento silábico em crianças em um período mais amplo do desenvolvimento da leitura utilizando uma tarefa de decisão lexical. Nesse sentido, é bastante relevante notar que o presente estudo conseguiu detectar um efeito de priming silábico no tempo de reação bastante cedo no desenvolvimento da leitura, já que as palavras precedidas por primes congruentes tenderam a ser reconhecidas 57 milissegundos mais rapidamente do que as palavras precedidas por primes incongruentes. Embora, numericamente, o efeito de priming tenha sido maior nas crianças mais novas, esse resultado se mostrou independente do ano escolar e da estrutura silábica inicial das palavras, já que não houve interação estatisticamente significativa entre as variáveis tipo de prime e ano escolar e nem entre o tipo de prime e a estrutura silábica inicial.

Em um estudo que comparou pseudopalavras comuns e pseudohomófonas (pseudopalavras com o mesmo som de palavras reais, p.ex., 'chícara' é uma pseudohomófona porque tem o mesmo som que a palavra real 'xícara'), Grainger, Lété, Bertrand, Dufau e Ziegler (2012) observaram que embora 0 efeito das 
pseudohomófonas tenha sido estatisticamente significativo em todos os anos escolares investigados ( $1^{\circ}$ ao $5^{\circ}$ ano), ele foi maior nos anos iniciais. Como o efeito de priming silábico e o efeito de pseudohomófonas podem ser considerados efeitos relacionados à recuperação dos sons durante a leitura, é possível que o efeito de priming silábico decresça naturalmente ao longo do tempo também. Isso explicaria porque, no presente estudo, o efeito de priming silábico foi numericamente maior no $1^{\circ}$ e $2^{\circ}$ anos.

Ao se considerar a porcentagem de erros, a variável mais importante foi a estrutura silábica inicial, sendo que, de uma forma geral, as crianças de todos os anos erraram mais nas palavras com estrutura silábica inicial do tipo CV do que do tipo CVC. O priming silábico não teve efeito estatisticamente significativo na porcentagem de erros das crianças do $3^{\circ}$ e $4^{\circ}$ anos. Já para as crianças do $1^{\circ}$ e $2^{\circ}$ anos, 0 priming silábico teve efeito inverso ao esperado na porcentagem de erros, sendo que as palavras precedidas por primes congruentes geraram mais erros do que as precedidas por primes incongruentes. O fato do efeito de prime ser inverso no TR e na porcentagem de erros das crianças mais novas levanta a possibilidade de que essas tenham apresentado um efeito de troca entre rapidez e precisão (speed accuracy trade off). De qualquer forma, é importante salientar que mesmo considerando apenas as crianças do $3^{\circ}$ e $4^{\circ}$ ano escolares, as crianças do presente estudo são mais novas do que as crianças de outros estudos que investigaram algum tipo de efeito silábico (Chetail \& Mathey, 2009; Maïonchi-Pino et al, 2010). Destarte, o presente estudo traz evidências de que desde cedo as crianças falantes do português brasileiro parecem demonstrar algum tipo de sensibilidade ao processamento silábico durante a leitura, seja como medida pelo efeito do priming silábico no tempo de reação, seja como medida pelo efeito do tipo de estrutura da sílaba inicial das palavras na porcentagem de erros.

No que diz respeito à estrutura da sílaba inicial das palavras é curioso que as crianças do $1^{\circ}$ ao $4^{\circ}$ ano tenham errado mais nas palavras com sílabas iniciais do tipo CV do que nas com sílabas iniciais do tipo CVC. Afinal, é intuitivo pensar que uma sílaba do tipo CV é menos complexa do que uma sílaba do tipo CVC. No estudo de Maïonchi-Pino et al. (2010) as crianças francesas do $5^{\circ}$ ano responderam mais rapidamente quando as letras eram congruentes com a primeira sílaba das palavras que tinham uma estrutura do tipo CVC, independente da frequência de ocorrência dessa sílaba, enquanto nas crianças do $1^{\circ}$ e do $3^{\circ}$ ano, isso ocorreu apenas quando a frequência de ocorrência da sílaba era alta. Embora não tenha realizado testes estatísticos tendo a porcentagem de erros como medida, no estudo de Maïonchi-Pino et al. as palavras com uma sílaba inicial do tipo CV também apresentaram maior porcentagem de erros do que as do tipo CVC (ver tabela 2, na p.75 do estudo de Maïonchi-Pino et al., 2010). 
Assim sendo, não é a primeira vez que se encontra uma vantagem de processamento para as palavras com sílaba inicial do tipo CVC.

Uma possível explicação para essa vantagem de processamento para as palavras com sílaba inicial do tipo CVC em relação às palavras com sílaba inicial do tipo CV é que, tanto no presente estudo quanto no de Maïonchi-Pino et al. (2010), o efeito se deva a um maior número de fonemas compartilhados na condição congruente para as palavras CVC. Afinal, via de regra, as sílabas do tipo CV teriam dois fonemas e as do tipo CVC teriam três fonemas. Assim sendo, no presente estudo, os primes congruentes para as palavras com sílaba inicial CVC compartilhariam um fonema a mais com essa sílaba do que os primes congruentes para as palavras com sílaba inicial CV. Algo similar pode ter ocorrido no estudo de Maïonchi-Pino et al., já que as palavras com sílabas iniciais do tipo CVC na condição congruente compartilhavam mais letras e possivelmente mais fonemas com as letras de comparação do que as palavras com sílaba inicial CV. Como no presente estudo o efeito de estrutura silábica não pode ser separado do tamanho da unidade silábica, talvez seja melhor se falar em um efeito silábico-fonêmico, seja para o efeito do priming silábico, seja para o efeito da estrutura silábica. De qualquer forma, é importante pontuar que é difícil imaginar como algum estudo poderia fazer essa separação, afinal uma sílaba CVC tenderá a ter mais fonemas do que uma sílaba CV.

Outra pergunta que se levantou na presente pesquisa foi se existiria relação entre o processamento fonológico e o processamento silábico. Nesse caso, é importante ressaltar que nenhuma variável relacionada ao processamento fonológico (isso é, a consciência fonológica ou a memória de trabalho fonológica) se correlacionou significativamente com o efeito de priming silábico em nenhum dos anos estudados. Além disso, ao se considerar o efeito da estrutura silábica inicial, a única variável que se correlacionou com esse efeito foi a memória de trabalho fonológica e, mesmo assim, apenas no $3^{\circ}$ e $4^{\circ}$ anos.

Considerando-se a ausência de correlação tanto entre a consciência fonológica e o efeito de priming silábico quanto entre a consciência fonológica e o efeito da estrutura silábica, poder-se-ia argumentar que a influência da consciência fonológica durante o desenvolvimento dos processos psicológicos subjacentes à leitura é diacrônica e não sincrônica. Isso é, ter uma boa consciência fonológica ajuda as crianças a ler palavras novas (tal como na hipótese do autoensinamento de Share, 1995) e a aumentar o seu léxico, mas os processos automáticos envolvidos na leitura "on-line" (como os processos lexicais e sublexicais envolvidos no mapeamento de um padrão visual em um padrão fonológico e/ou ortográfico) sofreriam pouca influência ou não seriam sensíveis a essa variável.

No que diz respeito à memória de trabalho fonológica, apesar dessa não ter apresentado relação com o efeito de priming silábico, essa 
correlacionou-se positivamente com o efeito da estrutura silábica. A correlação positiva entre a memória de trabalho fonológica e uma medida on-line como o efeito da estrutura silábica corrobora a ideia de que uma eficiente codificação fonológica na memória de trabalho capacita o leitor a manter uma representação precisa dos fonemas associados com letras ou grupos de letras (Wagner \& Torgesen, 1987), repercutindo positivamente em sua leitura. Nesse caso, uma boa memória de trabalho fonológica pode ter facilitado o processamento das sílabas iniciais do tipo CVC, resultando em menos erros nas palavras iniciadas com essas sílabas. Por outro lado, a ausência de correlação entre a memória de trabalho fonológica e o efeito de priming silábico poderia ser explicada pelo fato desse efeito não colocar demandas à memória, já que a palavra alvo seguia-se imediatamente ao prime. De qualquer forma, esse parece ter sido o primeiro estudo a avaliar tais tipos de relação e assim sendo, esse resultado deve ser considerado com cautela, já que não se tem um parâmetro claro de comparação em relação a outros estudos.

Por fim, cabe ressaltar que as correlações observadas no $3^{\circ}$ e $4^{\circ}$ anos entre a consciência fonológica e a memória de trabalho fonológica e entre a porcentagem de erros e essas duas medidas têm a direção esperada e servem de indício de que a ausência de correlação das primeiras com o efeito de priming silábico provavelmente não se deve à falta de poder estatístico. Além disso, é importante enfatizar que a maior correlação entre uma variável fonológica e o efeito de priming silábico foi de apenas -0,09. Esse resultado, se replicado em outros estudos, pode ser importante para se compreender a relação da consciência fonológica e da memória de trabalho fonológica com a leitura hábil. Afinal, se elas não se relacionam com o processamento on-line durante a leitura, fortalecese a hipótese de que elas são importantes para os períodos iniciais da alfabetização (p.ex., na aprendizagem do princípio alfabético), mas que depois é a experiência continuada de leitura que é a responsável pela automatização dos processos lexicais.

É importante ressaltar que os resultados desse estudo devem ser tomados com cautela, afinal, o mesmo foi um dos primeiros a investigar os efeitos do processamento silábico em crianças tão novas. Em especial, é importante considerar que uma das limitações dessa pesquisa é que ela foi conduzida exclusivamente com crianças de uma escola particular, sendo importante investigar se esses resultados se generalizam para crianças de escolas públicas. Dessa forma, seria importante que esses resultados possam ser replicados em pesquisas futuras com falantes do português e também em falantes de outras línguas menos regulares. Outra limitação do presente estudo, foi ter utilizado apenas uma tarefa para investigar 0 acesso lexical. Assim sendo, uma investigação relevante seria tentar replicar esse estudo utilizando uma tarefa de leitura em voz alta ao 
invés da tarefa de decisão lexical que foi utilizada aqui. Afinal, é possível que a tarefa de leitura em voz alta, por colocar uma demanda maior à recuperação das representações fonológicas que são necessárias para a pronúncia correta dos estímulos, possa ser uma medida mais sensível aos efeitos do priming silábico e da estrutura silábica das palavras.

\section{Referências}

Álvarez, C., Carreiras, M., \& Perea, M. (2004). Are syllables phonological units in visual word recognition? Language and Cognitive Processes, 19, 427-452.

Andrews, S. (2006). From inkmarks to ideas: Current issues in lexical processing. New York, NY: Psychology Press.

Ashby, J., \& Rayner, K. (2004). Representing syllable information during silent reading: Evidence from eye movements. Language and Cognitive Processes, 19, 391-426.

Barbosa, T., Miranda, M., Santos, R., \& Bueno, O. (2009). Phonological working memory, phonological awareness and language in literacy difficulties in Brazilian children. Reading and Writing, 22, 201-218.

Bryant, P., \& Bradley, L. (1987). Problemas de leitura na criança. Porto Alegre: Artes Médicas.

Cardoso-Martins, C. (1995). Sensitivity to rhymes, syllables and phonemes in literacy acquisition in Portuguese. Reading Research Quarterly, 30, 808-828.

Cardoso-Martins, C., Haase, V., \& Wood, G. (1998). Bateria de testes de habilidades fonológicas adaptada da Phonological Assessment Battery. Manuscrito não-publicado.

Carreiras, M., \& Grainger, J. (2004). Sublexical representations and the 'front end' of visual word recognition. Language and Cognitive Processes, 19, 321-331.

Carreiras, M., \& Perea, M. (2004). Naming pseudowords in Spanish: Effects of syllable frequency. Brain and Language, 90, 393-400.

Carreiras, M., \& Perea, M. (2011). Efectos de la estructura silábica em el priming silábico. Revista de Logopedia, Foniatría y Audiologia, $31,22-27$.

Carreiras, M., Álvarez, C., \& de Vega, M. (1993). Syllable frequency and visual word recognition in Spanish. Journal of Memory and Language, 32, 766-780.

Chetail, F., \& Mathey, S. (2009). The syllable frequency effect in visual word recognition of French words: A study in skilled and beginning readers. Reading and Writing, 22, 955-973.

Conrad, M., \& Jacobs, A. (2004). Replicating syllable frequency effects in Spanish in German: One more challenge to 
computational models of visual word recognition. Language and Cognitive Processes, 19, 369-390.

Conrad, M., Carreiras, M, Tamm, S., \& Jacobs, A. (2009). Syllables and bigrams: Orthographic redundancy and syllabic units affect visual word recognition at different processing levels. Journal of Experimental Psychology: Human Perception and Performance, 35, 461-479.

Forster, K., \& Forster, J. (2003). DMD X: A windows display program with millisecond accuracy. Behavior Research Methods, Instruments and Computers, 35, 116-124.

Frederickson, N., Frith, U., \& Reason, R. (1997). Phonological Assessment Battery. Windsor, UK: NFER-Nelson.

Grainger, J., Lété, B., Bertrand, D., Dufau, S., \& Ziegler, J. (2012). Evidence for multiple routes in learning to read. Cognition, 123, 280-292.

González, J., \& Valle, I. (2000). Word identification and reading disorders in the Spanish language. Journal of Learning Disabilities, 33, 44-60.

Justi, C., \& Justi, F. (2009a). Contagem da frequência dos bigramas em palavras de quatro a seis letras do português brasileiro. Psicologia em pesquisa (UFJ F), 3, 81-95.

Justi, C., \& Justi, F. (2009b). Os efeitos de lexicalidade, frequência e regularidade na leitura de crianças falantes do português brasileiro. Psicologia: Reflexão e Crítica, 22(1), 36-43.

Justi, C., \& Roazzi, A. (2012). A contribuição de variáveis cognitivas para a leitura e a escrita no português brasileiro. Psicologia: Reflexão e Crítica, 25, 605-614.

Kudo, M., Lussier, C., \& Swanson, L. (2015). Reading disabilities in children: A selective meta-analysis of the cognitive literature. Research in Developmental Disabilities, 40, 51-62.

Lúcio, P. S., \& Pinheiro, A., M. V. (2011). Vinte anos de estudo sobre - reconhecimento de palavras em crianças falantes do português: uma revisão da literatura. Psicologia: Reflexão e Crítica, 24(1), 170-179.

Maïonchi-Pino, N., Magnan, A., \& Écalle, J. (2010). Syllable frequency effects in visual word recognition: Developmental approach in French children. Journal of Applied Developmental Psychology, $31,70-82$.

Melo, R., \& Correa, J. (2013). Consciência fonológica e a aprendizagem da leitura e escrita por adultos. Estudos e Pesquisas em Psicologia, 13(2), 460-479.

Perea, M. (1999). Tiempos de reacción y psicología cognitiva: dos procedimientos para evitar el sesgo debido al tamaño muestral. Psicológica, 20, 13-21.

Perfetti, C. A., \& Hart, L. (2001). The lexical basis of comprehension skill. In D. S. Gorfein, (Ed), On the consequences of meaning 
selection: Perspectives on resolving lexical ambiguity. Washington, DC: American Psychological Association.

Pinheiro, A. (1996). Contagem de frequência de ocorrência e análise psicolinguística de palavras expostas a crianças na faixe préescolar e séries iniciais do $1^{\circ}$ grau. São Paulo: Associação Brasileira de Dislexia.

Roazzi, A., Roazzi, M., Justi, C., \& Justi, F. (2013). A relação entre a habilidade de leitura e a consciência fonológica: estudo longitudinal em crianças pré-escolares. Estudos e Pesquisas em Psicologia, 13(2), 420-446.

Rosenthal, R. (1984). Meta-analytic procedures for Social Research. London: Sage.

Rosner, J., \& Simon, D. (1971). The auditory analysis test: an initial report. Journal of Learning Disabilities, 4, 384-392.

Salles, J., \& Parente, M. (2006). Funções neuropsicológicas em crianças com dificuldades de leitura e escrita. Psicologia: Teoria e Pesquisa, 22, 153-162.

Seymour, P. (2005). Early reading development in european orthographies. In M. Snowling, \& C. Hulme (Eds.), The Science of Reading: A Handbook (pp.296-315).Oxford: Blackwell.

Share, D. (1995). Phonological recoding and self-teaching: Sine qua non of reading acquisition. Cognition, 55, 151-218

Wagner, R., \& Torgesen, J. (1987). The nature of phonological processing and its causal role in the acquisition of reading skills. Psychological Bulletin, 101, 192-212.

Wechsler, D. (2002). WISC-III: Escala de inteligência Wechsler para crianças. Manual/David Wechsler, $3^{\text {a }}$ ed.; Adaptação e padronização brasileira, $1^{\text {a }}$ ed.; Vera Lúcia Marques de Figueiredo. São Paulo: Casa do Psicólogo.

\section{Endereço para correspondência \\ Francis Ricardo dos Reis J usti}

Universidade Federal de Juiz de Fora

Departamento de Psicologia / Instituto de Ciências Humanas e Letras

Rua José Lourenço Kelmer, s/n, Campus Universitário, São Pedro, CEP 36036-900, Juiz de Fora - MG, Brasil

Endereço eletrônico: francisjusti@gmail.com

\section{Cláudia Nascimento Guaraldo J usti}

Universidade Federal de Juiz de Fora

Departamento de Psicologia / Instituto de Ciências Humanas e Letras

Rua José Lourenço Kelmer, s/n, Campus Universitário, São Pedro, CEP 36036-330, Juiz de Fora - MG, Brasil

Endereço eletrônico: claudia.ngjusti@gmail.com

Recebido em: 30/06/2016

Reformulado em: 17/11/2016

Aceito em: $17 / 11 / 2016$ 
Francis Ricardo dos Reis Justi, Cláudia Nascimento Guaraldo Justi

\section{Notas}

* Doutorou-se em Psicologia Cognitiva pela Universidade Federal de Pernambuco (2009). Atualmente é Professor Adjunto na Universidade Federal de Juiz de Fora e exerce a função de Coordenador do curso de Pós-graduação em Psicologia da UFJF. É Editor Associado da revista Psicologia em Pesquisa e tem experiência na área de Psicologia Cognitiva, atuando principalmente nos seguintes temas: reconhecimento visual de palavras, memória, linguagem (oral e escrita) e processos psicológicos básicos de uma forma geral.

** Doutorou-se em Psicologia Cognitiva pela Universidade Federal de Pernambuco (2009). Atualmente é professora adjunta e coordenadora do curso de Psicologia da Universidade Federal de Juiz de Fora. Tem experiência na área de psicologia do desenvolvimento humano e desenvolve pesquisas, principalmente, sobre os seguintes temas: processos cognitivos subjacentes ao desenvolvimento da leitura e da escrita e modelos computacionais de reconhecimento visual de palavras. 